\title{
Prevalence of pulmonary tuberculosis and associated risk factors in prisons of Gamo Goffa Zone, south Ethiopia: A cross-sectional study
}

\author{
Zerihun Zerdo 1, *, Girmay Medhin ${ }^{2}$, Adane Worku², Gobena Ameni \\ ${ }^{1}$ Department of Medical Laboratory Science, College of Medicine and Health Science, Arbaminch University, Arbaminch, Ethiopia \\ ${ }^{2}$ Akililu Lemma Institute of Pathobiology, Addis Abeba University, Addis Abeba, Ethiopia
}

\section{Email address:}

zedozerihun@gmail.com (Z.Zerdo),gobenachimdi2009@yahoo.co.uk (G. Ameni),gtmedhin@yahoo.com (G. Medhin), adanewrk@yahoo.com (A. Worku)

\section{To cite this article:}

Zerihun Zerdo, Girmay Medhin, Adane Worku, Gobena Ameni. Prevalence of Pulmonary Tuberculosis and Associated Risk Factors in Prisons of Gamo Goffa Zone, South Ethiopia: A Cross-Sectional Study. American Journal of Health Research. Vol. 2, No. 5, 2014, pp. 291-297. doi: 10.11648/j.ajhr.20140205.21

\begin{abstract}
Background: There is limited information regarding tuberculosis (TB) in prisons in Ethiopia. Therefore, the purpose of the present study was to estimate the prevalence of pulmonary tuberculosis in prisons and assess associated risk factors among inmates suspected for pulmonary tuberculosis in Gamo Goffa Zone, Southern Ethiopia. Methods: A crosssectional study design was used to recruit 124 inmates in Gamo Goffa Zone, Southern Ethiopia, between November 1 and March 3, 2011. During the study period there were a total of 3817 prisoners in the three prisons of the study Zone. Inmates were eligible for the study if they had cough for more than or equal to two weeks during the study period. Structured questionnaire was used to collect data on risk factors of pulmonary tuberculosis. Sputum samples were collected from suspected inmates and examined using sputum smear microscopy and culture on Lowenstein-Jensen media. Results: The prevalence of pulmonary TB among inmates who had cough for at least 2-weeks was 19.4\% (24/124). Extrapolation of the finding implies that there were 629 pulmonary tuberculosis cases during the survey period per 100,000 prisoners. Smoking, previous history of treatment for pulmonary tuberculosis, poor ventilation of the cell, cough for more than four weeks before diagnosis and decreased body mass index were significantly associated with increased odds of being positive for pulmonary tuberculosis. Conclusion: The estimated prevalence of pulmonary tuberculosis was about 8 folds higher than its counterpart in the community which was in line with the findings of previous studies in Ethiopia. This implies the need for tuberculosis control measures to be targeted on factors driving tuberculosis in southern Ethiopia: improving ventilation status of cells in prisons, monitoring nutritional status of prisoners and restricting access to smoking.
\end{abstract}

Keywords: Prevalence, Risk Factors, Pulmonary Tuberculosis, Prison, Ethiopia

\section{Background}

Tuberculosis (TB) is an airborne, infectious disease caused by bacteria of the genus Mycobacterium. It continues to be a major public health problem in the worldwide [1]. One-third of the world population was infected by Mycobacterium but only $10 \%$ were predicted to be sick with active TB [2-4]. Every year, more than 9 million people are suffering from active TB which can spread to others while coughing, talking, sneezing, spiting and singing [1]. Mortality and morbidity due to TB are more common in developing countries: $95 \%$ of TB cases and $98 \%$ of TB related deaths occur in such countries [1, 5]. The number of TB cases in prisons constitutes the major proportion of the national burden of the disease [6].

The estimated prevalence of PTB in prisons was several folds higher than that in the general community [7]. For example, in prisons of Zambia, the magnitude of PTB was more than 10 times that in the general population [8]. In Russia more than half of new national TB cases occur in prisons [6]. Moreover, prisons play significant role in the epidemiology of MDR-TB, defined as M. tuberculosis resistant to at least isoniazid and rifamicin. This fact threatens TB control in prisons because of high treatment 
failure and death rates, and complexities in diagnosis and treatment $[9,10]$.

TB propagates in prisons because prisons concentrate TB, disseminate TB, make TB worse and prisons export TB [11]. Some of the factors which fuel the transmission of TB within prisons include high representation of people from low socioeconomic backgrounds, high rates of substance abuse, underlying poor health or nutrition, overcrowding, poor hygiene and inadequate ventilation. There are prisons where inmates cured of PTB choose to remain in the cells with active TB so as to avoid the worst of the disparate overcrowding elsewhere $[12,13]$.

There is limited information about TB in prisons in Ethiopia. Previous studies in Ethiopia reported the prevalence of PTB as 1913 and 1482 per 100, 000 prisoners in Eastern and North Ethiopia respectively [14,15]. However, the findings from these studies cannot represent the situation in Ethiopia since the country is the most diversified in terms of population and geography. Thus, there is need to accurately define specific factors driving $\mathrm{TB}$ and the prevalence of the problem in prisons of Gamo Goffa Zone. Gamo Goffa is one of the 14 zones in South Nations Nationalities and People's Regional state (SNNPR) and its administrative center is Arba Minch Town. Based on the 2007 national Census Gamo Goffa Zone has a total population of $1,593,104$, of whom 793,322 were men and 799,782 were women; with an area of $11,010.99$ square kilometers [16]. During the study period there were three prisons in the zone. Study participants to answer the question under study were recruited from these three prisons.

\section{Materials and Methods}

\subsection{Study Design and Recruitment of Participants}

A cross-sectional study design was used to collect information required to answer the research question under investigation. There were 3817 inmates in the three prisons between November 1, 2011 and March 3, 2012 and all inmates were eligible for the study. Most of the detainees spend the day time on different developmental activities making access to each prisoner difficult if not impossible during the day time. Hence, health committee members, present in each cell, were given an assignment of recruiting inmates into the study. They were oriented on to recruit inmates who had cough to the prison clinics. The prison clinic health workers interviewed inmates who had cough more than or equal to two weeks. Three eligible inmates for interview from prison three failed to produce sputum specimen and thus were not included in the study. Hence, 124 inmates willing to participate, interviewed and submitted sputum specimen were participants of the current study.

\subsection{Sputum Collection and Processing}

Three sputum specimens were collected from every consenting TB suspect using coded and sterile plastic containers by laboratory personnel according to WHO guidelines [17]. Portion of the collected specimen was used for direct smear microscopy immediately and the remaining portion was stored at $4{ }^{0} \mathrm{C}$ in refrigerator until transported for culture. The stored portions of three sputum samples of each inmate were pooled in one container, transported using ice box within seven days of the sample collection to the culture laboratory and subjected to digestion and decontamination using equal volume of $4 \% \mathrm{w} / \mathrm{v}$ sodium hydroxide. Sodium hydroxide eliminates organic debris and the unwanted normal flora. After centrifugation for 15 minutes at 3000 RPM the supernatant was decanted and the sediment was resuspended. Sodium hydroxide treated specimen was neutralized by $2 \mathrm{~N}$ Hydrochloric acid by using Red phenol as an indicator. Each sputum specimen was inoculated both on LJ glycerol and pyruvate based media. The inoculated culture media was then incubated at $37^{0} \mathrm{C}$ up to 8 weeks and assessed weekly for growth of Mycobacterium. The growth of Mycobacterium was confirmed by colony characteristics and culture smear [17].

\subsection{The Questionnaire}

A structured questionnaire was used to collect data on risk factors of TB from the study participants. The questionnaire had sections on socio-demographics, behaviors of study participants, situation of prison and morbidity related factors. The questionnaire was prepared in English, translated into local languages and then back translated to English to check accuracy.

\subsection{Statistical Analysis}

All completed questionnaires were checked for completeness before computerizing the data using EpiData version 3.1 software. After exporting the computerized data into STATA version 11, frequencies and results from crosstabulations were used to monitor transcription errors. Logistic regression and fisher's exact test were used as appropriate to assess association between independent variables and PTB positivity. Variables for multivariable logistic regression were selected based on statistical significance in univariable logistic regression. Odds ratio and corresponding 95\% confidence intervals were used to quantify the degrees of association between target potential risk factor and PTB positivity. Results with p-value less than 0.05 were considered as being statistically significant.

\subsection{Ethical Considerations}

The study protocol was approved by research ethics review committee of ALIPB before commencement of the study (Reference number of the approval letter: IRB/1/2011-2012). Permission to conduct the research was obtained from prison authorities after giving them recommendation letter written by ALIPB. An informed consent was obtained from the study participant before collecting specimen and interviewing. 


\section{Results}

\subsection{Socio Demographic and Behavioral Factors}

During the study period there were 3817 prisoners in the three prisons of Gamo Goffa Zone (1863 in prison 1, 640 in prison 2 and 1314 in prison 3 ) and $97.1 \%$ of the inmates were males. After screening the whole prison inmates for having cough for at least 2-weeks, 124 inmates were recruited into the current study. Except two females recruited from prison 3, all the study participants were male. Prevalence of suspected inmates for PTB was $3.2 \%$ (95\%CI: $2.7 \%$ to $3.8 \%$ ) and bacteriologically confirmed PTB among suspected inmates was 19.4\% (95\%CI: $12.8 \%$ to $27.4 \%$ ). Extrapolating the current result to 100,000 prisoners brings the prevalence of PTB to 629 per 100,000 prisoners.

Age of the study participants ranges from 18 to 95 years and its distribution is skewed to the right with the median age of 28 years. Among the study participants $54.8 \%$ were married, $40.3 \%$ were unable to read and write, $86.3 \%$ were residents of rural area and $37.1 \%$ smoked cigarette in their life time for an average of 12.5 years $(\mathrm{sd}=10.4$ years). Of the study participants who had ever smoked cigarette, $45.6 \%$ continued to smoke and on average they smoke 4.4 cigarettes (standard deviation of 4 cigarettes) per day. In univariable and multivariable analysis none of the socio demographic and behavioral factors were significantly associated with being positive for active PTB with the exception of smoking (Tables 1 and 4).

Table 1. Association of socio-demographic and behavioral factors of inmates and PTB among prisoners of Gamo Goffa Zone, N=124.

\begin{tabular}{|c|c|c|c|c|}
\hline Factors & No. $(\%)$ evaluated & No. (\%) positive & Crude OR(95\%CI) & P_value \\
\hline \multicolumn{5}{|l|}{ Age (in years) } \\
\hline $15-24$ & $52(41.9)$ & $9(17.3)$ & Reference & \\
\hline $25-34$ & 21(16.9) & $4(19.0)$ & $1.12(0.30-4.14)$ & 0.860 \\
\hline $35-44$ & $18(14.5)$ & $4(22.2)$ & $1.36(0.36-5.13)$ & 0.645 \\
\hline$>44$ & $33(26.6)$ & $7(21.2)$ & $1.29(0.43-3.87)$ & 0.654 \\
\hline \multicolumn{4}{|l|}{ Marital status* } & 1.000 \\
\hline Single & $48(38.7)$ & $8(16.7)$ & Reference & 0.362 \\
\hline Married & $68(54.8)$ & 13(19.1) & $1.18(0.45-3.12$ & \\
\hline Others & $8(6.45)$ & $3(35.5)$ & $3(0.59-15.16)$ & \\
\hline \multicolumn{4}{|c|}{ residence place before incarceration } & 0.848 \\
\hline Rural & $107(86.3)$ & 21(19.6) & Reference & \\
\hline Urban & 17(13.7) & $3(17.6)$ & $0.88(0.23-3.33)$ & \\
\hline \multicolumn{4}{|c|}{ Occupation before imprisonment* } & 0.236 \\
\hline Student & $16(12.9)$ & $4(25.0)$ & Reference & \\
\hline Farmer & $89(71.8)$ & $19(21.3)$ & $0.81(0.24-2.81)$ & \\
\hline Self employed & 19(15.3) & $1(5.3)$ & $0.17(0.2-1.68)$ & \\
\hline \multicolumn{4}{|l|}{ Level of Education* } & 0.6 \\
\hline Uneducated & $50(40.4)$ & $12(24.0)$ & Reference & \\
\hline Primary & $52(41.9)$ & $9(17.3)$ & $0.66(0.25-1.74)$ & \\
\hline Secondary\& above & $20(17.7)$ & $3(13.6)$ & $0.50(0.12-1.99)$ & \\
\hline \multicolumn{4}{|c|}{ Have you Ever smoke Cigarette? } & 0.028 \\
\hline Yes & $46(37.1)$ & $4(8.7)$ & $3.62(1.15-11.37)$ & \\
\hline No & $78(62.9)$ & $20(25.6)$ & Reference & \\
\hline
\end{tabular}

* P-value computed using Fisher exact test; $\mathrm{OR}=$ odds ratio; $\mathrm{CI}=$ confidence interval

\subsection{Prison Related Factors}

On average, there were 116 inmates per cell in the study prisons, which is equivalent to about one inmate per square meter of a cell. Duration of stay in the current prison was positively skewed with the median of 15 months. All cells in the three prisons had window. Seven of the study participants reported that windows of their cells are always closed. Inmates staying in cells where windows were open sometimes or always had significantly decreased risk to have active PTB as compared to those staying in cells where windows were closed at all times. Majority of the study participants $(57.3 \%)$ reported having food support 
from their families with an average frequency of 1.5 times per month (Table 2 and Table 4).

Table 2. Association of prison related factors of inmates and PTB among prisoners of Gamo Goffa Zone, N=124.

\begin{tabular}{lllc}
\hline Factors & No $(\%)$ evaluated & No(\%) positive & Crude OR(95\%CI) \\
\hline Prison code & & & P_value \\
One & $85(68.5)$ & $12(14.1)$ & Reference \\
Two & $15(12.1)$ & $5(33.3)$ & $3.04(0.88-10.46)$ \\
Three & $24(19.4)$ & $7(29.2)$ & $2.50(0.86-7.31)$ \\
Ventilation status of cell & & & 0.077 \\
Window closed at all time & $7(5.6)$ & $5(71.4)$ & Reference \\
Window open sometimes & $90(72.6)$ & $15(16.7)$ & $0.08(0.01-0.45)$ \\
Window open always & $27(21.8)$ & $4(14.8)$ & $0.07(0.01-0.49)$ \\
Have you Food support from family? & & & 0.004 \\
Yes & $71(57.3)$ & $15(21.1)$ & 0.007 \\
No & $53(42.7)$ & $9(17.0)$ & 0.564 \\
Did you Shared cell with PTB patient? & & & Reference \\
No & $84(67.7)$ & $16(19.0)$ & $0.31(0.52-3.27)$ \\
Yes & $40(32.3)$ & $8(20.0)$ & 0.900 \\
\hline
\end{tabular}

* P-value computed using Fisher exact test; $\mathrm{OR}=$ odds ratio; $\mathrm{CI}=$ confidence interval

In the current study, mean number of previous history of incarceration for study participants in prisons other than where they were incarcerated during the study period was 1.3 times (minimum of 1 and maximum of 3 ). Of the six prisoners with previous history of incarceration in other prisons, one was incarcerated three times and the rest were incarcerated once. The average length of stay in these prisons was 23.2 months. Forty of the study participants had history of sharing the same cell with PTB cases and $40.3 \%$ had history of sharing the same cell with chronically coughing inmates. Duration of stay in the same cell with PTB cases and with chronically coughing inmates was skewed to the right with the median of 5 months for chronically coughing and 6.5 months for PTB cases.

\subsection{Morbidity Related Factors}

Seventy two percent $(89 / 124)$ of the study participants received treatment for the symptoms that they were feeling during the survey period (Table 4). The main reasons forwarded by those who were not treated was that it was self limited, the health committee of the prisons did not let them to visit clinic unless they were severely ill and bed ridden and lack of awareness about the disease. Twenty three study participants had previous history of treatment for PTB and 9 of them had PTB before incarceration. Inmates who had previous history of PTB had 6.6 times increased odds of developing active PTB compared to those who had not (Table 4). All participants who suffered from active PTB previously completed their treatment except one. Body mass index (BMI) was another factor significantly associated with active PTB.

Table 3. association of morbidity related factors of inmates and PTB among prisoners of Gamo Goffa Zone, N=124.

\begin{tabular}{|c|c|c|c|c|}
\hline Factors & No. $(\%)$ evaluated & No. $(\%)$ positive & Crude OR(95\%CI) & P_value \\
\hline \multicolumn{4}{|c|}{ Duration of cough before diagnosis } & 0.007 \\
\hline 2-4 weeks & $68(54.8)$ & $7(10.3)$ & Reference & \\
\hline$>4$ weeks & $56(45.2)$ & $17(30.4)$ & $3.80(1.44-10.00)$ & \\
\hline \multicolumn{4}{|c|}{ Have you Received treatment for current complaint? } & 0.068 \\
\hline Yes & $89(71.8)$ & $21(23.6)$ & Reference & \\
\hline No & $35(28.2)$ & $3(8.6)$ & $0.30(0.08-1.09)$ & \\
\hline \multicolumn{4}{|c|}{ How many times you visited clinic for complaint? } & 0.163 \\
\hline $1-3$ times & $58(65.2)$ & $11(19.0)$ & Reference & \\
\hline$>3$ times & $31(34.8)$ & $10(32.3)$ & $2.03(0.75-5.52)$ & \\
\hline \multicolumn{4}{|c|}{ TB symptoms before admission to prison? } & 0.120 \\
\hline No & $81(65.3)$ & $19(23.5)$ & Reference & \\
\hline Yes & $43(34.7)$ & $5(11.6)$ & $0.43(0.15-1.24)$ & \\
\hline \multicolumn{4}{|c|}{ Are you Previously diseased (PTB)? } & 0.002 \\
\hline No & $101(81.4)$ & $14(13.9)$ & Reference & \\
\hline Yes & $23(18.5)$ & $10(43.5)$ & $4.78(1.76-12.98)$ & \\
\hline \multicolumn{4}{|c|}{ Have you contact with TB patient at home?* } & 0.359 \\
\hline Yes & $20(16.1)$ & $2(10.0)$ & Reference & \\
\hline No & $104(83.9)$ & $22(21.1)$ & $2.41(0.52-11.20)$ & \\
\hline \multicolumn{4}{|l|}{$\mathrm{BMI}\left(\mathrm{kg} / \mathrm{m}^{2}\right)$} & 0.018 \\
\hline$<18.5$ & $10(8.1)$ & $5(50.0)$ & Reference & \\
\hline$\geq 18.5$ & $114(91.9)$ & $19(16.7)$ & $0.2(0.05-0.76)$ & \\
\hline
\end{tabular}

* P-value computed using Fisher exact test; $\mathrm{OR}=$ odds ratio; $\mathrm{CI}=$ confidence interval 
Table 4. predictors of active PTB among prisoners of Gamo Goffa Zone, N=124

\begin{tabular}{|c|c|c|c|c|}
\hline Factors & No.tested (\%) & No. positive (\%) & Adjusted OR(95\%CI) & P_value \\
\hline Have you Ever smoke Cigarette? & & & & 0.021 \\
\hline Yes & $46(37.1)$ & $4(8.7)$ & $4.90(1.27-18.90)$ & \\
\hline No & $78(62.9)$ & $20(25.6)$ & Reference & \\
\hline \multicolumn{5}{|l|}{ Ventilation status of cell } \\
\hline Window closed at all time & $7(5.6)$ & $5(71.4)$ & Reference & \\
\hline Window open sometimes & $90(72.6)$ & $15(16.7)$ & $0.05(0.01-0.37)$ & 0.004 \\
\hline Window open always & $27(21.8)$ & $4(14.8)$ & $0.05(0.00-0.48)$ & 0.010 \\
\hline Duration of cough before diagnosis & & & & 0.025 \\
\hline 2-4 weeks & $68(54.8)$ & $7(10.3)$ & Reference & \\
\hline$>4$ weeks & $56(45.2)$ & $17(30.4)$ & $3.93(1.19-12.95)$ & \\
\hline Are you Previously diseased (PTB)? & & & & 0.002 \\
\hline No & $101(81.4)$ & $14(13.9)$ & Reference & \\
\hline Yes & $23(18.5)$ & $10(43.5)$ & $6.56(1.98-21.71)$ & \\
\hline $\operatorname{BMI}\left(\mathrm{kg} / \mathrm{m}^{2}\right)$ & & & & 0.036 \\
\hline$<18.5$ & $10(8.1)$ & $5(50.0)$ & Reference & \\
\hline$\geq 18.5$ & $114(91.9)$ & $19(16.7)$ & $0.15(0.03-0.88)$ & \\
\hline
\end{tabular}

BMI of the study participants was normally distributed with the mean of $21.5 \mathrm{~kg} / \mathrm{m}^{2}\left(95 \%\right.$ CI of $\left.21.1-21.9 \mathrm{~kg} / \mathrm{m}^{2}\right)$ indicating that most detainees were in the normal range of nutritional status (i.e. $8.1 \%$ were underweighted, $85.5 \%$ well nourished and $6.4 \%$ were over weighted). However, the mean BMI of patients with active PTB was significantly lower than the mean BMI of patients without active PTB $\left(17.4 \mathrm{~kg} / \mathrm{m}^{2}\right.$ versus $21.9 \mathrm{~kg} / \mathrm{m}^{2} ; \mathrm{p}$-value $\left.=0.009\right)$

\section{Discussion}

In the current cross-sectional study the prevalence of confirmed PTB among the TB suspected inmates in Gamo Goffa Zone was $19.4 \%$ (24/124. The risk factors identified for PTB were previous history of anti-PTB treatment, living in a cell where windows remain continuously closed, decreased body mass index, having cough for more than 4 weeks before diagnosis or initiation of treatment and habit of smoking cigarette.

Extrapolation of the current finding indicates that the prevalence of PTB in prisons of the study area was about 8folds higher than the prevalence in the general community in southern Ethiopia [18]. It indicates an increased transmission of TB which could lead to outbreak in the prisons unless immediate action is taken [19].The prevalence of pulmonary TB in the study population is in consistent with the findings of studies in Bangladesh, Zambia and central prisons in Pakistan [19, 20, 21] while other studies from district prisons of Pakistan, jail of Lahore Malawi, reported significantly lower prevalence [22, 23]. The prevalence of suspected inmates for pulmonary TB $(24 / 3817,0.6 \%)$ is lower than previously reported symptom based prevalence in prisons of Eastern Ethiopia [14] and Northern Ethiopia [15]. This might partly be explained by lower prevalence of HIV infection $(1.7 \%$ in adult population) in the south Ethiopia from where the detainees enter in to the prisons [24].

In the current study frequency of PTB cases was higher among male detainees than among female detainee. Large number of male PTB cases in this study might have been resulted from crowding of detainees in male cells (average of 118 male inmates per a cell but maximum of 20 female inmates per a cell) besides the negative effect of poor ventilation. This was consistent with the scenario that overcrowding predisposes to PTB [12].

In agreement with most previous studies, smoking was significant risk factor of PTB in the current study. In Russia majority of the detainees had started to smoke early in their life. The findings of two studies in Pakistan [25, 26], one study in Bangladesh [21] and one study in Gambia [27] were in agreement with the findings of the present study. However, the finding of previous study in prison of Eastern Ethiopia was in contrary to the current findings [14]. One possible explanation might be differential chat chewing habits of the study participants. Majority of the study units in the eastern Ethiopian study had chat chewing habit which is mostly accompanied by smoking. The number of nonsmokers in eastern Ethiopia prisons was very small and not enough to show smoking as risk factor for PTB [14].

In the current study duration of stay in the prisons was not significantly associated with PTB positivity. However, studies in Bangladesh, Pakistan and eastern Ethiopia reported positive association between staying for long duration in prisons and PTB [14, 25, 21]. In contrast to most studies, one study from the Cameroon has indicated that long duration of stay in prison has slight protective effect on PTB as compared to those stayed for $\leq 12$ months [28]. This protective effect might be due to increased awareness about PTB by those stayed for longer time in the prison than those who were sentenced newly.

In line with the finding from studies in Pakistan [25, 21], Russia [29], Brazil [30] and Bangladesh [21] the present study indicated that the risk of PTB is increased for inmates who had a previous history of treatment for PTB. This indicates that majority of the disease in the prison might be due to reactivation and it might imply an increased risk for such cases to be MDR-TB [31]. Thus, it is an implication for drug susceptibility test for such cases to be undertaken than merely providing treatment. Unlike finding of the present study, there was no such association in previous 
studies in eastern Ethiopian and in Cameroon [14, 15, 28 ]. This might be due to the absence of cells to segregate inmates who were taking anti- TB treatment in to separate cells until cases were no more infectious.

The strength of this study was inclusion of the entire prison population in the screening process rather than taking a random sample. This method of recruiting study participants reduces the problem of sampling errors. One of the limitations of the current study emanates from the study design being cross-sectional as this hinders the ability to establish causal link between PTB and factors which are significantly associated with PTB. Another limitation of this study is the risk of recall bias. The response of study participants about risk factors might not be always correct, (i.e. there is possibility of over or under reporting). In the current study we could not assess the magnitude of PTB attributable to HIV/AIDS though HIV is highly prevalent in the SSA prisons. Thus, the findings of the current study should be interpreted in light of the above limitations and strength.

\section{Conclusion}

In conclusion this study revealed that the prevalence of PTB in the three prisons of Gamo Goffa Zone is about 8 times the prevalence in the general population in south Ethiopia. It indicates that there is high transmission of TB in the prisons.

\section{Acknowledgements}

First, we would like to thank all laboratory technicians and other professionals working in prisons of Arbaminch clinic, Chencha clinic, Goffa clinic and those working in ALIPB TB laboratory for their due support during the data collection and processing. Lastly, we would like to thank ALIPB for its financial support which was used to conduct this study.

\section{Authors' Contributions}

ZD has contributed to the conception of the study question, designed the study, collected the data, analyzed the data, interpreted the data and drafted the manuscript. GA is involved in conception of the research question, interpreted the data and drafted the manuscript. GM is involved in conception of the study question, analyzed the data, interpreted the data and drafted

\section{References}

[1] The Henry Kaiser foundation. 2009. The Global Tuberculosis Epidemic. Fact sheet. http://www.kff.org/globalhealth/upload/7883-02.pdf. Accessed 10 November 2011.

[2] United States Agency for international development/
Ethiopia

(USAID). Tuberculosis profile. 2006. http://pdf.usaid.gov/p df_docs/pdaci535.pdf. Accessed 21 December 2011.

[3] Dara M, Grezemaska M, Kimerling ME, Reyes M, Zagoriskiy A. 2009. Gridlines for control of Tuberculosis in prisons. http://pdf.usaid.gov/pdf_docs/PNADP462.pdf. Accessed 18 January 2012.

[4] Sohail M. Tuberculosis: A re-emerging enemy. Journal of Molecular and Genetic Medicine.2006; 2(1): 87-88.

[5] Minister of health $(\mathrm{MoH})$ : Implementation Guideline for TB/HIV; Collaborative Activities in Ethiopia. Addis Abeba, Ethiopia; 2007

[6] Coker R, McKee M, Atun R, et al. Risk factors for pulmonary tuberculosis in Russia: case-control study. British Medical Journal. 2006; 332 (7533): 85-87.

[7] Grady, J.O., Hoelscher, M., Atun, R et al.Tuberculosis in prisons in sub-Saharan Africa the need for improved health services, surveillance and control. Tuberculosis. 2011; 91(2): 173- 178 doi:10.1016/j.tube.2010.12.002.

[8] Zumla A.Tuberculosis in prisons in sub-Saharan Africa - a potential time bomb. South African Medical Journal. 2011; 101(2).

[9] United Nations Agency of International Development (UNAID) reference group on HIV and and human rights: HIV and tuberculosis: ensuring universal access and protection of human rights. 2010. http://data.unaids.org/pub/ExternalDocument/2010/2010032 4_unaidsrghrtsissuepapertbhrts_en.pdf. Accessed 10 October 2011

[10] Suchindran S, Brouwer ES, Rie AV. Is HIV Infection a Risk Factor for Multi-Drug Resistant Tuberculosis? A Systematic Review. PLoS ONE. 2007; 4(5):e5561. doi:10.1371/journal.pone.0005561

[11] Grady JO, Maeurer R, Atun R, et al. Tuberculosis in prisons: anatomy of global neglect. European Respiratory Journal. ${ }^{\mathrm{b}}$. 2011; 38 (4): 752-754.

[12] Minister of Health (MoH): Guidelines for Tuberculosis Control in New Zealand. Wellington 6145, New Zealand, 2010 .

[13] Moszynski P. Zambian prisons 'threaten public health' because of high rates of TB and HIV. British Medical Journal. 2010; 340: c2225. doi: http://dx.doi.org/10.1136/bmj.c2225

[14] Abebe DS. Prevalence and associated risk factors of pulmonary tuberculosis among prisoners in eastern Ethiopia. International Journal of Tuberculosis and Lung Disease. 2009; 13(10):1313- 1315.

[15] Moges B, Amare B, Asfaw F, et al. Prevalence of smear positive pulmonary tuberculosis among prisoners in North Gondar Zone Prison, northwest Ethiopia. BMC Infectious Diseases. 2012; 12:352

[16] Central statistical agency (CSA). 2007. http://www.csa.gov. et/newcsaweb/images/documents/pdf_files/regional/SNNPR 1.pdf .Accessed 23 September 2011

[17] World Health Organization (WHO). Basic laboratory procedures in clinical bacteriology. Geneva, Switzerland: $2^{\text {nd }}$ edition, 2003 
[18] Shargie EB, Yassin MA, Lindtjorn B. Prevalence of smearpositive pulmonary tuberculosis in a rural district of Ethiopia'. International Journal of Tuberculosis and Lung Disease. 2006; 10 (1): 87-92.

[19] WHO regional officer for Europe. 2011. Prison and health. [http://www.euro.who.int/en/what we do/health topics/health determinants/prisonsand health/facts and figures.Accessed 20 October 2011.

[20] Habeenzu C, Mitarai S, Lubasi D. Tuberculosis and multidrug resistance in Zambian prisons. International Journal of Tuberculosis and Lung Disease. 2007; 11(11): $1216-1220$

[21] Banu S, Hossain A, Khaja M, Uddin M. Pulmonary Tuberculosis and Drug Resistance in Dhaka Central Jail, the Largest Prison in Bangladesh. PLoS ONE. 2010; 5(5): e10759. doi:10.1371/journal.pone.0010759

[22] Banda HT, Gausi F, Harries AD, Salaniponi FM. Prevalence of smear-positive pulmonary tuberculosis among prisoners in Malawi: a national survey. International Journal of Tuberculosis and Lung Disease. 2009; 13(12):1557-1559.

[23] Manzoor S, Tahir Z, Anjum A. Prevalence of HIV and tuberculosis among jail inmates in lahore - pakistan. Journal of Biomedical science. 2009; 25: 36 - 41 .

[24] Federal HIV/AIDS Prevention and Control Office (FHAPCO). (2013). HIV Prevalence and Incidence, Adult Population in Ethiopia and regions. National Factsheet. http://www.etharc.org/resources/healthstat/nationalfactsheet/ 13nationalfactsheet2010. Accessed 14 February 2013

[25] Shah SA, Mujeeb SA, Mirza A, Nabi KG, Siddiqui Q. Prevalence of pulmonary tuberculosis in Karachi juvenile jail, Pakistan. Journal of Eastern medtranean health. 2003; $9(4)$.
[26] Hussain H, Akhtar S, Nanan D. Prevalence of and risk factors associated with Mycobacterium tuberculosis infection in prisoners, North West Frontier Province, Pakistan. International Journal of Epidemiology .2003; 32(5): 794- 799 doi:10.1093/ije/dyg247.

[27] Hill PC, Jackson-Sillah D, Donk SS, Out J, Adegbola RA, Lienhardt C. Risk factors for pulmonary tuberculosis: a clinic-based case control study in The Gambia. BioMedical Center of Public Health. 2006; 6: 156 doi:10.1186/14712458-6-156.

[28] Noeske J, Kuaban C, Amougou G, Piubello A, Pouillot R. Pulmonary tuberculosis in the Central Prison of Douala, Cameroon. East African Medical Journal. 2006; 83(1): 2530 .

[29] Drobniewski FA, Balabanova YM, Ruddy MC at al. Tuberculosis, HIV seroprevalence and intravenous drug abuse in prisoners. European Respiratory Journal. 2005; 26 (2): 298-304 doi: 10.1183/09031936.05.00136004

[30] Sanchez A, Gerhardt G, Natal S, et al. Prevalence of pulmonary tuberculosis and comparative evaluation of screening strategies in a Brazilian prison. International Journal of Tuberculosis and Lung Disease. 2005; 9(6): 633639.

[31] Pleumpanupat W, Jittimanee S, Akarasewi P, et al. Resistance to anti-tuberculosis drugs among smear-positive cases in Thai prisons 2 years after the implementation of the DOTS strategy. International Journal of Tuberculosis and Lung Disease. 2003; 7(5): 472-477. 